\title{
Development of an Isotope-Dilution Flow-Injection Electrospray/ Mass Spectrometric Method for the Accurate Determination of Glucosamine in Pharmaceutical Formulation
}

\author{
Guinam Kim, ${ }^{\dagger}$ Byungioo Kim, ${ }^{*}$ Seonghee Ahn, Euijin Hwang, and Yongseong Kim ${ }^{\dagger}$ \\ Division of hetrology for Qtality Life, Korea Research Institute of Standards and Science, Fuseong, \\ Daejeon 305-600. Korea. ${ }^{*}$ E-mail: bungjooiä kriss.re.hr \\ ${ }^{\dagger}$ Department of Chemistry, Kytngnam Lniversity, Hasan, Kymgnam 631-701, Korea \\ Received October 7, 2008, Accepted December 18, 2008
}

\begin{abstract}
An isotope-dilution flow-injection electrospray/mass spectrometric method was developed for the accurate detenmination of glucosamine contents in phannaceutical formulations. Samples were extracted by methanol. After spiking glucosamine- $-1-{ }^{13} \mathrm{C}_{1}$ as an internal standard, the extracts were then analyzed by flow-injection ESI/MS in a selected ion monitoring ( $\mathrm{SIM}$ ) mode to detect $[\mathrm{M}+\mathrm{H}]^{+}$ions of the analyte and its isotope analogue at $\mathrm{m} / \mathrm{z} 180$ and $\mathrm{m} / \mathrm{z} \mathrm{l} 8 \mathrm{l}$, respectively. Confirmatory measurements were made by selectively monitoring the collisionally induced dissociation channels of $\mathrm{m} / \mathrm{z} \quad 180 \rightarrow \mathrm{m} / \mathrm{z} 72$ and $\mathrm{m} / \mathrm{z} \quad 181 \rightarrow 73$, respectively, to test the possibility of bias in the SIM method due to matrix interferences, but any significant bias in the SIM mode was not observed. Repeatability and reproducibility studies showed that the flow-injection ESI/MS method is a reliable and reproducible method which can provide a typical method precision of $1.0 \%$. Other results for the method validation are reported.
\end{abstract}

Key Words: Glucosamine. Nutritional supplement. Flow-injection ID-ESI/MS. Method validation

\section{Introduction}

Glucosamine is a natural amine sugar extracted from the chitin in Cnistaceans such as shrimps and crabs. As researches have shown that glucosamine is efficacious in the treatment of degenerative joint diseases, ${ }^{1.2}$ glucosamine is currently one of the popular dietary supplements. As numerous glucosamine products are marketed as nutritional supplements with pharmacentical formulations for the prevention and treatment of osteoarthritis and degenerative joint diseases, ${ }^{\text {j.t }}$ the glucosamine contents in those products should be labeled on the products in accordance with food labeling laws and are tested by regulatory bodies and contracted laboratories for consumer protection and safety. Therefore, a definitive method for the accurate determination of glucosamine contents is required as a reference method to harmonize the analytical results.

High performance liquid chromatographic (HPLC) methods have been used for the analysis of glucosamine in dosage forms. ${ }^{2.56}$ However typical UV/VIS detectors have shown limitation because glucosamine does not contain a chromophore to absorb UV/VIS light. Therefore, refractive index detectors have been employed for the HPLC analysis of glucosamine. In addition to the detection difficulty. a relatively cumbersome normal phase LC separation is required for the direct analy sis of glucosamine in phanmaceutical products. ${ }^{2.5 .8}$ Pre-column derivatization has been employed to overcome the detection difficulty and/or to adopt a reverse phase LC separation. ${ }^{9.11}$ Recently. a normal phase LC separation with ESL/MS detection method has been employed for the direct determination of glucosamine in human plasma. ${ }^{12}$ The mass spectrometric detection has been proved to be more specific and sensitive than those spectroscopic detections.

In this paper. a simple method is developed based on a flow-injection ESI/MS with isotope dilution techniques as a candidate reference method for the accurate determination of glucosamine contents in nutritional supplements in dosage forms. In this method, a flow-injection stage substitute the usual LC separation step preceding the ESI/MS detection as the high selectivity of the mass spectrometric detection is expected to elininate interferences from pharnaceutical formulations whose matrix are relatively simple. Glucosamine- $1-{ }^{13} \mathrm{C}$ is used as an internal standard for employing isotope dilution techniques to improve the accuracy of analy'tical results. Also. adopting the isotope labeled analogue of the target analyte as an internal standards is expected to eliminate the possible bias due to ion suppression/enhancement by matrix interference in the ionization processes. For the validation of the method. the results from the flow-injection ESI/MS in the SIM mode chosen as a primary detection mode was compared with those in the SRM mode used as a confirmaton detection mode. The repeatability and reproducibility of the method were also tested to evaluate the metrological quality of the method.

\section{Experimental}

Materials. D-Glucosamine hydrochloride $(99+\%)$ from Sigma-Aldrich (St. Louis, MO, USA) was used as a primary reference material without further purification. D-glucosamine- $1{ }^{13} \mathrm{C}$ was also purchased from Sigma-Aldrich. HPLC grade organic solvents (methanol and acetonitrile) were obtained from Burdick and Jackson (Muskegon, MI. USA). Filter cartridges (PURDISC NYL 25 FILTER $25 \mathrm{~mm} 0.45 \mu \mathrm{m}$ ) were purchased from Whatman (Clifton. NJ. USA). Nutritional supplements in tablet or capsule forms from several manufacturers were purchased from local markets and were used as saniples.

Calibration Standarl Solutions. The standard solution used in this study was prepared and verified according to a pro- 
cedure maintained in our laboratory, ${ }^{13.16}$ the national metrology institute of Korea. The brief description of the procedure is as follows. Four glucosamine standard solutions of a $100 \mathrm{mg} / \mathrm{kg}$ level in methanol were gravimetrically prepared independently. A glucosamine- $1-{ }^{13} \mathrm{C}$ standard solution of a $100 \mathrm{mg} / \mathrm{kg}$ level was prepared in the same way. For each of the four glucosamine standard solutions. two isotope ratio standard solutions with 1:1 isotope ratio were prepared by gravimetrically mixing with the glucosamine- $1-{ }^{13} \mathrm{C}$ standard solution. We cross-checked the isotope ratio standard solutions to test the self-consistencies of the standard solutions and the isotope ratio standard solutions by using the flow-injection ESI/MS method established in this study. Based on the cross-check results. an isotope ratio standard solution was selected and used in sample analy sis

Sample Prepanation and Clean-up. Tablet samples or contents in capsules were homogenized by grinding with a laboratory mill prior to subsampling. $0.1 \mathrm{~g}$ of homogenized sample was weighed into a $120 \mathrm{~mL}$ glass bottle and $100 \mathrm{~mL}$ of methanol was added into it. Though water or water/acetonitrile $(50 / 50)$ was used in previous studies as extraction solvents, methanol was chosen as an extraction solvent in this study after comparison of extraction efficiencies of the three solvents. The exact amounts of sample and extraction solvent were determined by weighing the bottle before and after addition of each of them. The bottle was caped tightly, and was subject to shaking for complete mixing. sonification for 1 hour in a water bath at room temperature. and sonification for 1 hour at $50^{\circ} \mathrm{C} .0 .5 \mathrm{~mL}$ of the supernatant of sample extract was pipetted into a vial. An appropriate amount of the glucosamine- $1{ }^{13} \mathrm{C}$ standard solution was spiked to the vial so that the ratio of glucosamine to glucosamine- $1-{ }^{13} \mathrm{C}$ was close to 1.0 . The content of the vial was well mixed and passed through a filter cartridge (PURDISCNYL 25 FILTER $25 \mathrm{~mm}$ $0.45 \mu \mathrm{m}$ ). A portion of the filtered extract was then diluted with methanol to a level which is convenient for ESI/MS analy sis ( $10 \mathrm{mg} / \mathrm{kg}$ in this study). The same dilution was done for the isotope ratio standard solution.

Flow-Injection ESI/MS Analysis. The LC/tandem MS used in this stidy was an API 2000 mass spectrometer from Applied Biosystems (Forster City, CA, USA) combined with an 1100 Series LC system from Agilent Technologies (Palo Alto, CA, USA) through its electrospray ionization interface. We adopted the mass spectrometer with a triple quadnupole mass analyzer as analyzers of this type are known to provide a better quantitative performance compared to ion-trap type or time-of-flight type analyzers. In this study, $100 \%$ methanol mobile phase stream from the LC pump at the flow rate of 0.3 $\mathrm{mL} / \mathrm{min}$. was connected to the ESI interface without a LC column. Sample extracts and calibration standard mixtures were injected into the mobile phase stream in $10 \mu \mathrm{L}$ volume units by using an autosampler equipped in the LC system. The mass spectrometer was operated in the positive ion mode. For the principal measurement. MS was operated in the selected ion monitoring (SIM) mode for monitoring the $[\mathrm{M}+\mathrm{H}]^{+}$ions of glucosamine and glucosamine- $1-{ }^{13} \mathrm{C}$ at $\mathrm{m} / \mathrm{z} 180$ and 181 . respectively. To test bias due to matrix interferences. confimatory measurements was done in the selected reaction monitoring (SRM) mode by detecting the collisionally induced dissociation (CID) channels of the $[\mathrm{M}+\mathrm{H}]^{+}$ions to $\left[\mathrm{C}_{3} \mathrm{H}_{6} \mathrm{NO}\right]^{+}$ at $\mathrm{m} / \mathrm{z} 180 \rightarrow \mathrm{m} / \mathrm{z} 72$ and $\mathrm{m} / \mathrm{z} 181 \rightarrow 73$, respectively. For the SRM mode, the collision cell. the second quadrupole of the mass spectrometer. was filled with nitrogen gas at a pressure of $\sim 0.2 \mathrm{~Pa}\left(\sim 2.0 \times 10^{-3} \mathrm{mbar}\right)$ and the collision energy was adjusted to $27 \mathrm{eV}$.

\section{Results and Discussion}

Flow Injection ESI/MS. Full-scan mass spectra of glucosamine and glucosanine-1- ${ }^{13} \mathrm{C}$ were doninated by the protonated molecular ions $[\mathrm{M}+\mathrm{H}]^{-}$at $\mathrm{m} / \mathrm{z} 180$ and 181 . respectively. and the most intense peak in the $\mathrm{CID}$ product ion mass spectra of the $[\mathrm{M}+\mathrm{H}]^{-}$ions were at $\mathrm{m} / \mathrm{z}, 72$ and 73 , respectively. These results are in a good agreement with a previous study. ${ }^{12}$ In this study. the $[\mathrm{M}+\mathrm{H}]^{-}$ions at $\mathrm{m} / \mathrm{z} 180$ and 181 were selected for the mass spectrometric detection of glucosamine and glucosanine-1 ${ }^{13} \mathrm{C}$. respectively. The CID channels of $\mathrm{n} / \mathrm{z} 180 \rightarrow$ $\mathrm{m} / \mathrm{z} 72$ and $\mathrm{m} / \mathrm{z} \mathrm{I} 8 \mathrm{l} \rightarrow 73$ were chosen for the confinmatory measurements in the SRM mode.

Figure 1 shows signal profiles of MS in the SIM mode obtained by flow-injection of glucosamine standard solutions at various concentrations. Each signal profile has a peak which arises rapidly from 0.12 mimute to its maximum at 0.22 minute and decrease with a little tailing to the background level within 1.0 minute. The inset of the graph is a calibration curve for the peak area versus the concentration of glucosanine. The calibration curve shows a very good linearity, indicating that the flow-injection ESI/MS in the SIM mode can be used for the quantitative analysis of glucosanine. A sinular linearity was also observed when MS signals were detected in the SRM mode.

Figure 2 shows the typical profiles of \$IM and SRM signals of glucosamine and glucosamine- $1-{ }^{15} \mathrm{C}$ from an extract of a glucosanine product obtained from a local market. The profiles are similar to those obtained from standard solutions as shown in Figure 1.

To test the performance of the flow-injection ESI/MS detection for the IDMS analysis of glucosanine, the standard deviation of the area ratio of glucosanine and glucosanine- $1-{ }^{13} \mathrm{C}$

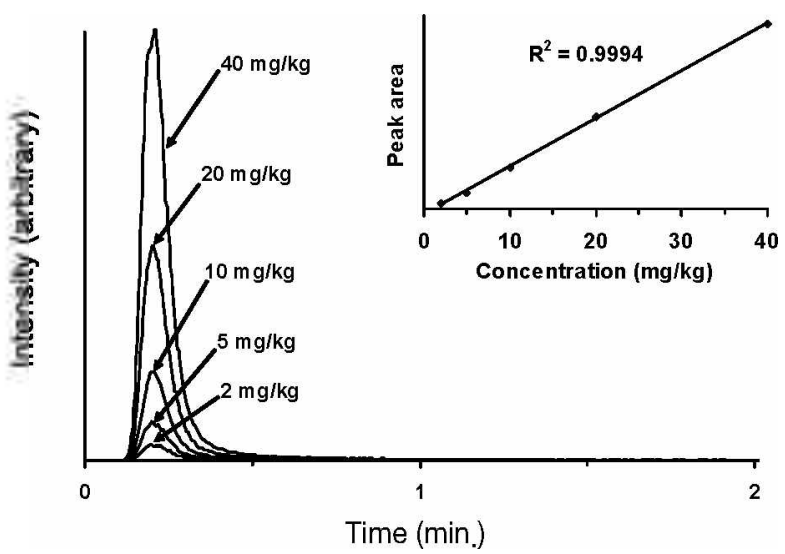

Figure 1. Glucosamine signal profiles of ESI/MS in the SIM mode at $\mathrm{m} / 2180$ obtained by flow-injection of glucosamine standard solutions with a series of concentrations. The inset of the graph is a calibration curve of the peak area versus the concentration of glucosamine. 
a) SIM mode detection

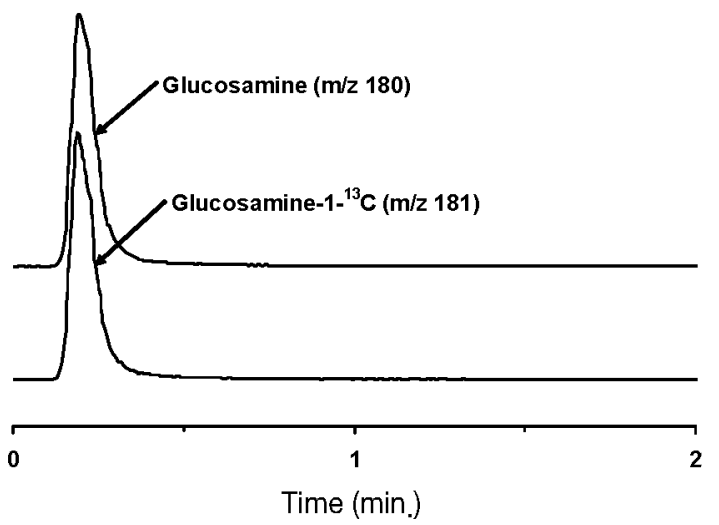

b) SRM mode detection

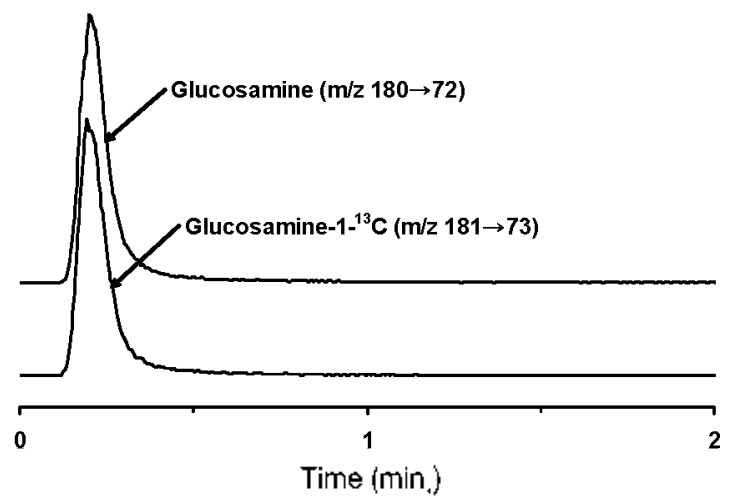

Figure 2. Typical profiles of MS-SIM and MS-SRM signals of glucosanine and glucosamine- $1-{ }^{13} \mathrm{C}$ from an extract of a glucosamine product obtained from a local market.

was evaluated from multiple runs of sample extracts and calibration standard mixtures. The relative standard deviation of the area ratio from both SM and SRM modes was typically around $0.8 \%$ for both sample extracts and calibration standard mixtures. The results indicate that the flow-injection ESI/MS method with isotope dilution techniques can provide a high metrological quality in glucosamine measurements. Therefore. we have chosen the isotope-dilution flow-injection ESI/MS in the SIM mode as a candidate reference method for the analy sis of glucosamine in pharmaceutical formulations.

Method Validation and Analytical Quality Check We carefully evaluated if the flow-injection ESI/MS in the SIM mode. combined with isotope dilution techniques, has an adequate quality as a reference method that can be used in national metrology institutes. As no matrix CRM with a certified value for glucosamine is available yet to our knowledge, "validation by using well-characterized standard or published methods" is not applicable. Therefore. careful evaluations of performance parameters of the method including repeatability. reproducibility, and sources of uncertainty are required.

Repeatability and Reproducibility. To test the repeatability and the reproducibility of the LC/MS method. a homogenized sample was prepared by using a procedure maintained in our laboratory for the preparation of certified reference materials. In brief. more than $200 \mathrm{~g}$ of glucosamine tablets, from a single batch of a manufacturer and with an adequate level of glu-
Table 1. Measurement results of glucosamine in a homogenized pharmacentical product by the flow-injection ESI/MS in the SIM mode in three different time periods

\begin{tabular}{|c|c|c|}
\hline & Subsample No. & $\begin{array}{c}\text { Measurement Results } \\
(\% \text { in } g / g)\end{array}$ \\
\hline & $\# 1$ & 54.2 \\
\hline & $\# 2$ & 54.1 \\
\hline & $\$ 3$ & 54.6 \\
\hline & $\# 4$ & 54.4 \\
\hline & Average & 54.3 \\
\hline & Standard deviation & $0.2\left(0.4 \mathrm{rel} \% \%^{b}\right)$ \\
\hline & Expanded uncertainty ${ }^{a}$ & $1.2\left(2.3 \mathrm{rel} \% 0^{\prime}\right)$ \\
\hline \multirow{7}{*}{ Period 2} & $\# 1$ & 54.4 \\
\hline & $\# 2$ & 53.3 \\
\hline & $\# 3$ & 54.3 \\
\hline & $\not 4$ & 54.5 \\
\hline & Average & 54.1 \\
\hline & Standard deviation & $0.5\left(1.0 \mathrm{rel} \% \%^{\mathrm{t}}\right)$ \\
\hline & Expanded uncertainty ${ }^{\sigma}$ & $1.7\left(3.1 \mathrm{rel} \%{ }^{b}\right)$ \\
\hline \multirow{7}{*}{ Period 3} & $\sharp 1$ & 54.0 \\
\hline & $\# 2$ & 54.2 \\
\hline & $\# 3$ & 54.7 \\
\hline & $\sharp 4$ & 54.8 \\
\hline & Average & 54.4 \\
\hline & Standard deviation & $0.4\left(0.7 \mathrm{rel} \%{ }^{4}\right)$ \\
\hline & Expanded uncertainty ${ }^{a}$ & $1.8\left(3.3 \mathrm{rel} \%{ }^{4}\right)$ \\
\hline \multirow{2}{*}{\multicolumn{2}{|c|}{$\begin{array}{c}\text { Average } \\
\text { Standard deviation among period }\end{array}$}} & 54.3 \\
\hline & & $0.14\left(0.35 \mathrm{rel}^{0} \%^{b}\right)$ \\
\hline
\end{tabular}

The expanded uncertainties are with a level of confidence of $95^{\circ}$ o. "The unit "rel $\%$ " indicates the relative percentage of the standard deviation or the uncertainty of the value in front of the parenthesis in comparison with the corresponding mean value.

cosamine. was homogenized by pulverization. sieving for selecting particles below $250 \mu \mathrm{m}$ and $\mathrm{V}$-mixing. The homogenized sanple was bottled into anber jars in $20 \mathrm{~g}$ unit. which was stored at $4 \mathrm{C}$ before use.

To test the repeatability of the candidate reference method, multiple subsamples were analyzed in a single period. To test reproducibility of the methods. the same repeatability test on the homogenized sample was carried out after a reasonable time interval of weeks to months. For the repeatability test in each time period. a new set of multiple standard solutions were prepared and used after verification by the self-consistency test described in the experimental section. Table 1 lists the measurement results obtained at three different time periods.

The relative standard deviation of the results obtained from the SIM mode within a time period is less than $1.0 \%$ of the corresponding mean values. indicating that the methods has excellent repeatability. Results from the SRM mode also showed the similar level of repeatability

The relative standard deviation of the means of the three different time periods was $0.14 \%$ for the SIM mode. which is smaller than the repeatability of within periods. indicating that the flow-injection ESI/MS method in the SIM mode has the high degree of reproducibility:

Limit of Quantification (LOQ). The linit of detection (LOD) 
and LOQ. measured as the concentrations corresponding to signal-to noise ratio of $3: 1$ and $10: 1$. respectively are 0.1 and $0.3 \mathrm{mg} / \mathrm{kg}$ in the extraction solvent. Therefore. the LOD and LOQ of this method are estimated to be 0.1 and $0.3 \%$ mass fraction of glucosamine in solid samples.

Confimatory Measurements. The homogenized sample and additional 7 glucosamine products in pharmaceutical formulation. which were all from different manufacturers and purchased from local markets. were analyzed by the flow-injection ESIMS in the SIM mode and the SRM mode. The results from the two detection modes are listed in Table 2 . The results from the principal measurements in the SIM mode and the confirmatory measurements in the SRM mode agree within their uncertainties. The results indicate that the SIM mode measurements do not show a significant bias in comparison with the SRM measurement which provide one more stage of selectivity: Therefore the possibility of matrix interferences

Table 2. Measurement results of glucosanine in commercial pharmaceutical formulas by the flow-injection ESI/MS in the SIM and SRM modes

\begin{tabular}{|c|c|c|c|}
\hline \multirow{2}{*}{ Products } & \multicolumn{2}{|c|}{${\text { Glucosamine Contents }(\% \text { in } g / g)^{\sigma}}^{\sigma}$} & \multirow{2}{*}{$\begin{array}{l}\text { Difeerence } \\
(\% \text { in } g / g)\end{array}$} \\
\hline & SIM mode & SRM mode & \\
\hline Sample in tablel & $54.3 \pm 0.2$ & $53.3 \pm 1.3$ & 1.0 \\
\hline Product A & $53.3 \pm 0.7$ & $54.7 \pm 0.9$ & 1.3 \\
\hline Product B & $24.3 \pm 0.8$ & $23.1 \pm 0.6$ & 1.2 \\
\hline Product C & $46.5 \pm 0.4$ & $47.0 \pm 0.8$ & 0.5 \\
\hline Product D & $28.7 \pm 0.7$ & $29.8 \pm 0.5$ & 1.2 \\
\hline Product E & $53.4 \pm 1.3$ & $53.6 \pm 2.6$ & 0.2 \\
\hline Product F & $83.1 \pm 3.5$ & $82.8 \pm 4.0$ & 0.3 \\
\hline
\end{tabular}

"The values following " $="$ are the expanded uncertainties of the preceding values with a level of confidence of $95^{\circ} \mathrm{O}$. from phamaceutical formulations is very small in the SIM mode measurement.

Test of Other Isomeric Interferences. The method developed in this study could not differentiate glucosamine from its isomeric compounds. such as galactosamine and mannosamine as their molecular ions, $[\mathrm{M}+\mathrm{H}]^{+}$. are at the same position of $\mathrm{m} / \mathrm{z} 180$. However, the two isomeric compounds are not expected to be present in most of commercial products as they are produced based on glucosamine sulfate or glucosamine hydrochloride extracted from the chitin in Crustaceans such as shrimps and crabs and the two isomeric compounds are not included in the extracted raw material. We analyzed most of glucosamine products available in the local market as shown in Table 2 with a LC/ESI/MS method established in our laboratory to test the possibility of the co-presence of those isomeric compounds. A manuscript for details of this method is under preparation. In brief, the three isomeric compounds were separated with a normal phase LC colunn (Phenomenex Luna $5 \mu \mathrm{m} \mathrm{NH} 2,150 \mathrm{~mm}$ length $4.6 \mathrm{~mm}$ I.D.) with isocratic mobile phase ( $10 \%$ of $20 \mathrm{mM}$ Ammonium acetate buffer solution with $\mathrm{pH} 10.5$ and $90 \%$ of acetonitrile) at $1.0 \mathrm{~mL} / \mathrm{min}$. ESI/MS as described in the text was used for the detection of LC eluent. Galactosamine, and nannosamine were not detected in all products tested in this study. Therefore. the flow-injection ESI/MS method can be applied to determine glucosamine in nutritional supplements which used glucosamine extracted from the chitin in Crustaceans as a raw material.

Uncertainty Sources. As a full discussion of the measurement uncertainty is beyond the scope of this article. only a brief description is given. Details on uncertainties sources and their evaluation methods in typical IDMS methods were described in previous articles published from this laboratory. ${ }^{13-16}$ Uncertainty sources of the results from the flow-injection ESI/MS

Table 3. Uncertainty sources in the ID-flow-injection ESI/MS for the detemination of glucosamine in pharmaceutical formulation

\begin{tabular}{|c|c|c|c|c|}
\hline Uncertainty Components & $\begin{array}{c}\text { Sources } \\
\text { (Evaluation Methods) }\end{array}$ & $\begin{array}{l}\text { Typical value } \\
\text { (Relative \%) }\end{array}$ & \multicolumn{2}{|c|}{$\begin{array}{c}\text { Relation with Repeatability and } \\
\text { Reproducibility }\end{array}$} \\
\hline \multirow[b]{2}{*}{ Glucosamine standard solution } & $\begin{array}{l}\text { Purity of the reference material } \\
\text { (from manufacturer's certificate) }\end{array}$ & $0.1 \%$ & \multicolumn{2}{|c|}{ Systematic uncertainty } \\
\hline & $\begin{array}{l}\text { Gravimetric preparation } \\
\text { (from cross-check of independent sets of } \\
\text { calibration solutions) }\end{array}$ & $0.6 \%$ & \multirow{2}{*}{$\begin{array}{l}\text { Systematic } \\
\text { effects to } \\
\text { multiple } \\
\text { measurements } \\
\text { within a time } \\
\text { period }\end{array}$} & \multirow{7}{*}{$\begin{array}{l}\text { Included in } \\
\text { reproducibility }\end{array}$} \\
\hline Isotope ratio standard & $\begin{array}{l}\text { Gravimetric mising (from cross-check of } \\
\text { independent sets of calibration standard } \\
\text { mixtures) }\end{array}$ & $0.5 \%$ & & \\
\hline Weight of sample taken for extraction & $\begin{array}{l}\text { Readability and linearity of the balance } \\
\text { (from the certificate of the balance) }\end{array}$ & $<0.01 \%$ & \multirow{5}{*}{$\begin{array}{l}\text { Included in } \\
\text { repeatability } \\
\text { within a time } \\
\text { period }\end{array}$} & \\
\hline Weight of sample estract taken for analysis & $\begin{array}{l}\text { Readability and linearity of the balance } \\
\text { (from the certificate of the balance) }\end{array}$ & $<0.01 \%$ & & \\
\hline $\begin{array}{l}\text { Weight of glucosamine-1- }-^{13} \mathrm{C} \text { standard sol- } \\
\text { ution spiked into sample extract }\end{array}$ & $\begin{array}{l}\text { Readability and linearity of the balance } \\
\text { (from the certificate of the balance) }\end{array}$ & $<0.01 \%$ & & \\
\hline $\begin{array}{l}\text { Peak area ratio of glucosamine and glucos- } \\
\text { amnine- } 1-{ }^{12} \mathrm{C} \text { from isotope ratio standard }\end{array}$ & $\begin{array}{l}\text { Standard deviation of multiple measure- } \\
\text { ments (typically from } 4 \text { runs) }\end{array}$ & $0.4 \%$ & & \\
\hline $\begin{array}{l}\text { Peak area ratio of glucosamine and glucos- } \\
\text { amnine- } 1-{ }^{12} \mathrm{C} \text { of sample extract }\end{array}$ & $\begin{array}{l}\text { Standard deviation of multiple measure- } \\
\text { ments (typically from } 4 \text { runs) }\end{array}$ & $0.4 \%$ & & \\
\hline
\end{tabular}

${ }^{a}$ Relationships of each uncertainty sources with the repeatability and the reproducibility are based on the measurement protocol used in this study. 
method in SIM mode are listed in Table 3. In the table. uncertainty sources are categorized according to their effects to repeatability and reproducibility test with following the measurement protocol described above. The expanded uncertainty in $95 \%$ confidence level is less than $+\%$ as shown in Table 1 . indicating that the method has a high metrological quality as a reference method.

\section{Conclusions}

An isotope dilution mass spectrometric method based on a flow-injection ESI/MS has been established and evaluated as a candidate reference method for the analysis of glucosamine in pharmaceutical products. The repeatability and reproducibility test results proved that the method provides a high metrological quality as a reference method. The candidate reference method will be used later in our laboratory for the certification of glucosamine in food supplemental reference materials.

\section{References}

1. Liang, Z: Leslie, $\mathrm{T}$ : Adebowale, A: Ashraf, M.; Eddington, N. D. J. Pham. Biomed Anal. 1999, 20,807.
2. Shao, Y: Alluri, R:: Mummert, M.: Koetter, U.: Lech, S. J. Phom. Bionted Anal 2004, 35, 625 .

3. Felson, D. T, Zhang, Y. Anthitis. Rheum 1998, H1, 1343.

4. Uebelhart, D;: Thonar, E. J.-M; Zhang, J.; Williams, I. M. Osteoanthitis Catilage 1998,6 (Supplement -1$), 6$.

5. Wu, Y.: Hussain, M.; Fassihi, R. J. Pham Biomed Anal 2005, $38,263$.

6. Zhu, X.; Cai, T.; Yang, T.; Su, Q. Carbohydr: Research 2005, 340, 1732

7. El-Saharty, Y. S.: Bary, A. A. Anal Chim Acta 2002, \$62, 125.

8. Crespo, M. O. P; Martínez, M. V.: Hernandez, J. L.; Yulsty, M. A. L. J. Chomatogr A 2006, 1116,189

9. Huang, T.-M.; Cai, L.; Yang, B.; Zhou, M.X.; Shen, Y.-F.; Duan, G.-L. Bionted. Chromatogr: 2006, 20, 215

10. Huang, T.-M.: Deng, C.-H.: Chen, N.-Z.; Liu, Z,; Duan, G.-L. J. Sep. Sci. 2006, 29, 2296

11. Tekko, I. A.: Bonner, M. C.: Williams, A. C. J. Pham Biomed. Anal. $2006,41,385$.

12. Roda, A.; Sabatini, L.; Barbieri, A.; Guardigli, M.; Locatelli, M.; Violante, F. S.; Rovati, L. C.; Persiani, S. J. Chromatogr: B 2006, 844,119

13. Kim, B.; Kim, D. H.; Choi, T. O.: So, H.-Y. Bull Konean Chem. Soc. $1999,20,910$.

14. Jung, M.; Kim, B.; Boo, D. W; So, H.-Y. Bull. Korean Chem. Soc. 2007, 28, 745

15. Park, S.: Kim, B.; So, H.-Y:; Kim, Y.-J.: Kim, I. Bull Korean Chem. Soc. 2007, 28, 737 .

16. Iung. P. G.: Kim, B.: Park, S.-R.: So, H.-Y.: Shi, L. H.: Kim, Y. Anal Biontal. Chem. 2004, $380,782$. 